\title{
Evaluating the Variation on Public Health's Perceived Field Need of Communicable Disease Reports
}

\author{
Uzay Kirbiyik ${ }^{\star 1,3}$, Roland Gamache ${ }^{2,3}$, Brian E. Dixon ${ }^{2,3}$ and Shaun Grannis ${ }^{1,3}$ \\ IIndiana University, School of Medicine, Indianapolis, IN, USA; 'Indiana University, School of Informatics, Indianapolis, IN, USA; \\ ${ }^{3}$ Health Informatics, Regenstrief Institute, Inc., Indianapolis, IN, USA
}

\section{Objective}

To assess communicable disease report fields required by public health practitioners and evaluate the variation in the perceived utility of these fields.

\section{Introduction}

Communicable disease surveillance is a core Public Health function. Many diseases must be reported to state and federal agencies (1). To manage and adjudicate such cases, public health stakeholders gather various data elements. Since cases are identified in various healthcare settings, not all information sought by public health is available (2) resulting in varied field completeness, which affects the measured and perceived data quality. To better understand this variation, we evaluated public health practitioners' perceived value of these fields to initiate or complete communicable disease reports.

\section{Methods}

We chose four diseases: Histoplasmosis, acute hepatitis B, hepatitis $\mathrm{C}$ and salmonella. We asked public health practitioners from Marion County Health Department (MCHD) of Indianapolis to list the fields they felt were necessary when submitting a communicable disease report. We then asked them to evaluate those fields using the following criteria:

Required - A critical case attribute, when missing or unknown, would make the task of initiating and/or closing a case impossible or exceedingly difficult.

Desired - A case attribute allowing more complete epidemiologic profiles to be developed but, if missing, would not prohibit initiating and/or closing a case.

Not applicable - A case attribute that is not usually collected to initiate and/or close a case for the particular condition.

To quantify the need for the fields, we assigned a number to each response as follows:
0 - Not applicable 1 - Desired
2- Required

We summed the numbers for each field for each disease and created a table for the perceived need of that field (table 1).

\section{Results}

The perceived needs table showed a difference between the fields needed to initiate or close a case. Moreover the perceived need for fields varied by disease as well. To assess the difference in perceived needs, we calculated the standard deviation of the fields (table 2).

\section{Conclusions}

Data quality is essential, not only for research but to support routine public health practice as well. Many factors affect data quality; one of them is perceived need of the information by Public Health Practitioners. Despite working with public health stakeholders from the same organization we observed variation in their perceived needs for these fields to initiate or close a communicable case. These results highlight another source of the problem regarding health information quality and its goodness of fit issues.

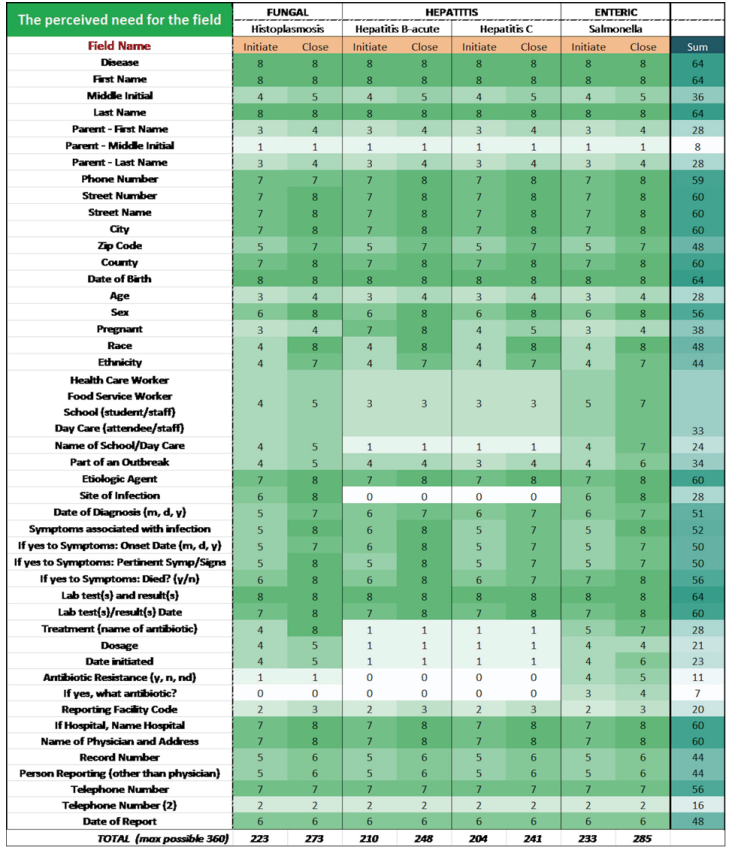

Table 1. Perceived need for the selected communicable disease reports fields. Higher numbers (darker color) reflect greater perceived need.

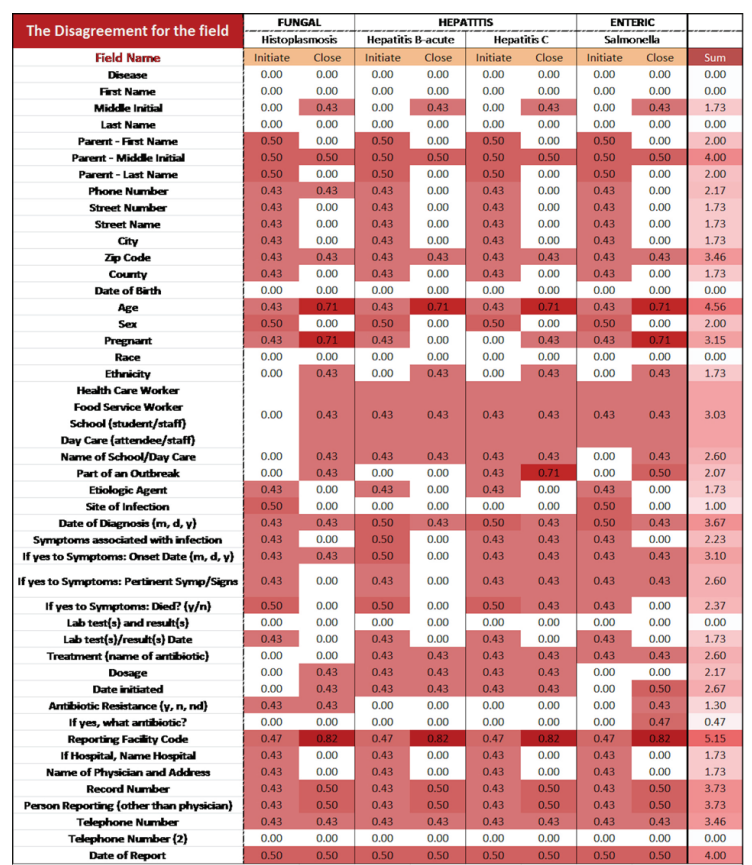

Table 2. Standard deviation of perceived need values for each field. Higher numbers reflect more disagreement among responses. 


\section{ISDS 2012 Conference Abstracts}

\section{Keywords}

completeness; Data quality; Communicable disease reports

\section{Acknowledgments}

We thank the MCHD of Indianapolis for their help with this research.

\section{References}

1. Morbidity and Mortality Weekly Report (MMWR) June 1, 2012 59(53);1-111 http://www.cdc.gov/mmwr/preview/mmwrhtml/mm59 53a1.htm

2. Indiana Confidential Report of Communicable Diseases - State Form 43823 (R2/11-96) https://forms.in.gov/Download.aspx?id=5082

3. Wang R Y, Strong D M, Guarascio L M. Beyond accuracy: what data quality means to data consumers. Journal of Management Information Systems 1996; 12 (4); 5-33.

\section{*Uzay Kirbiyik}

E-mail: ukirbiyi@iupui.edu 